University of Wollongong

Research Online

Faculty of Engineering and Information

Faculty of Engineering and Information

Sciences - Papers: Part A

Sciences

$1-1-2012$

Importance of the relative advantage of RFID as enabler of asset

management in the healthcare: Results from a Delphi Study

Samuel Fosso Wamba

University of Wollongong, samuel.fosso.wamba@neoma-bs.fr

Eric W. T Ngai

Hong Kong Polytechnic University, mswtngai@inet.polyu.edu.hk

Follow this and additional works at: https://ro.uow.edu.au/eispapers

Part of the Engineering Commons, and the Science and Technology Studies Commons

Research Online is the open access institutional repository for the University of Wollongong. For further information contact the UOW Library: research-pubs@uow.edu.au 


\title{
Importance of the relative advantage of RFID as enabler of asset management in the healthcare: Results from a Delphi Study
}

\begin{abstract}
Compared with bar coding technology, what is the importance of the relative advantage of radio frequency identification (RFID) in the healthcare sector? What is the effect of RFID technology on asset management-related processes in healthcare? What are the top-ranked asset management-related processes associated with the adoption and use of RFID technology in this sector? To answer these questions, a three-round Delphi study was conducted among experts working on RFID technology. In the study, a list of 12 processes related to the relative advantage of RFID and 10 processes related to RFIDenabled asset management applications in the healthcare sector were derived from literature and used in a questionnaire. Results indicate that all the top five processes related to the relative advantage of RFID and asset management applications reflect high levels of agreement.
\end{abstract}

\section{Keywords}

study, management, asset, enabler, rfid, advantage, importance, relative, healthcare, results, delphi

\section{Disciplines}

Engineering | Science and Technology Studies

\section{Publication Details}

Fosso Wamba, S. \& Ngai, E. W. T. (2012). Importance of the relative advantage of RFID as enabler of asset management in the healthcare: Results from a Delphi Study. The 45 Hawaii International Conferences on System Sciences (HICSS) (pp. 1-11). 


\section{Importance of the Relative Advantage of RFID as Enabler of Asset Management in the Healthcare: Results from a Delphi Study}

\author{
Samuel Fosso Wamba, Ph.D. \\ University of Wollongong, Wollongong, Australia \\ Rouen Business School, Rouen, France \\ samuel@uow.edu.au
}

\begin{abstract}
Compared with bar coding technology, what is the importance of the relative advantage of radio frequency identification (RFID) in the healthcare sector? What is the effect of RFID technology on asset management-related processes in healthcare? What are the top-ranked asset management-related processes associated with the adoption and use of RFID technology in this sector? To answer these questions, a three-round Delphi study was conducted among experts working on RFID technology. In the study, a list of 12 processes related to the relative advantage of RFID and 10 processes related to RFID-enabled asset management applications in the healthcare sector were derived from literature and used in a questionnaire. Results indicate that all the top five processes related to the relative advantage of RFID and asset management applications reflect high levels of agreement.
\end{abstract}

\section{Introduction}

The healthcare industry is one of the largest industries in many Western countries in terms of job creation, number of employees, and expenditure. In 2008, the industry generated 14.3 million jobs in the United States, with a potential increase of almost 3.2 million new jobs between 2008 and 2018 [1]. In 1963 , around $5 \%$ of the US gross national product (GNP) was allocated to healthcare expenses [2], and analysts predict that this figure will increase to $20 \%$ by 2017 [3]. Similarly, Canada's total public health spending in 2000 was estimated at $6 \%$ of the country's GNP, and that it can potentially increase to almost $7.1 \%$ by 2020 [4]. In Australia, the total public and private healthcare expenditure was estimated at $10 \%$ of the country's GDP, that is, an annual spending of about AUS\$ 65,000 million [5]. The healthcare sector is considered by many scholars and practitioners as one of the most complex industries because it involves multiple stakeholders and challenges, including patient safety; the ability to

\author{
Prof. Eric W. T. Ngai \\ Department of Management \& Marketing, Hong Kong \\ Polytechnic University, Hong Kong \\ Curtin University, Perth Western, Australia \\ mswtngai@inet.polyu.edu.hk
}

track and trace pharmaceuticals, medical devices, and flow of products from manufacturers to patients [5]; and the pervasive use of error-prone methods (e.g., manual data collection and paper-based healthcare) in providing critical healthcare services [6-8]. To overcome these challenges, the adoption and effective use of information technology (IT) is a key component of healthcare strategy. IT can facilitate the transformation of the healthcare sector [9] through better patient management, enhanced service quality, improved operational efficiency, and enhanced patient care (p. 446) [10]. RFID technology, a disruptive and open innovation [11] is regarded as the next wave of IT innovation that will broaden healthcare transformation [12, 13]. With recent advancements in nanotechnology, improvements in the capacity of integrated circuits and satisfaction of information needs in terms of accuracy have prompted renewed interest in the "relative advantage" of RFID technology compared with traditional automatic identification and data capture (AIDC) technology, such as bar coding. Relative advantage, which is the degree to which an innovation is better than existing practices in bringing benefits to an organization, is considered a key innovation characteristic that may motivate the decision to adopt an innovation (p. 233) [14]. For example, RFID technology offers improved capabilities including the identification of irrelevant line of sight, unique item-level product identification, multiple-tag product reading, enhanced data storage capability, and data read-and-write capabilities. In addition, the successful integration of RFID technology in intra- and inter-organizational business processes and information systems enables business process innovation, real-time data collection and sharing at the supply chain level, end-to-end item level tracking and tracing within the supply chain, and improved decision making. The high operational and strategic potential of RFID technology adoption are of considerable interest to academicians and practitioners. From an academic standpoint, this interest is manifested in the increased number of 
special journal issues on RFID in IT/IS/operation management/medical-related journals. However, very few studies have been conducted on the role of RFID technology as an enabler of improved asset management within the healthcare sector. In a recent analysis of peer-reviewed papers on RFID technology [15], we find that only $3.6 \%$ of the papers focused on issues related to the healthcare sector (17.8\%, the highest frequency, focused on the retail sector). The current paper represents an initial attempt to narrow down the existing knowledge gap observed in literature. More specifically, this study seeks answers to the following research questions:

1. Compared with bar coding technology, what is the importance of the relative advantage of RFID in the healthcare sector?

2. What is the effect of RFID technology on asset management-related processes in the healthcare sector?

3. What are the top-ranked asset management related processes associated with the adoption and use of RFID technology in the healthcare sector?

To address these research questions, this paper draws on a review of RFID technology, IT, and RFID technology potential in asset management-related processes, as well as on a Web-based Delphi study. The rest of the paper is organized as follows. Section 2 presents RFID technology. Section 3 discusses IT and RFID potential in healthcare with focus on asset management-related processes. Section 4 describes our research methodology. Section 5 presents the results and discussion, and Section 6 provides the conclusion and future research directions.

\section{RFID technology}

RFID is a "wireless automatic identification and data capture (AIDC)" technology (p. 615) [16] that uses radio frequencies to automatically identify individual products in real time [17]. A basic RFID system has three main components: (a) a tag, which can be attached to or embedded in the physical product to be identified; (b) a reader and its antennas, which interact with the tag without requiring a line of sight; and (c) middleware, which involves functions such as system management, RFID data filtering, RFID data aggregation, and interaction with intraand inter-organizational information systems (e.g., enterprise resource planning, warehouse management systems, logistics enterprise systems, and internal and external databases) to support intra- and interorganizational business regulations [18].

\section{IT potential in the healthcare sector: The case of RFID enabled smart asset management}

IT is a critical enabler of healthcare transformation. Some scholars have even suggested that the adoption and effective use of IT in the healthcare sector is "a critical goal of a 21 st-century healthcare system" (p. 79) [19]. IT can be used to support various activities within the healthcare sector, including the tracking of blood bags, monitoring of drug allergies [20], access to patient record transactions [21], improvement of healthcare decision making and healthcare resource allocation [22], and the facilitation of individual patient reminders and alerts [23]. In addition, IT offers prospects for the integration of patient information to promote quality of care and enhance efficiency [22]. More important, IT is critical in all decisions related to "managing, processing, retaining, and making accessible large amounts of disparate data to multiple end users" ( $p$. 1113) [20]. Thus, IT and other emerging technologies are considered "the biggest levers... that will re-make healthcare for the 21 st century" (p. 42) [24]. For example, IT not only allows for the fundamental redesign of end-to-end healthcare processes, but also fosters the "transition from institution-centric to patient-centric applications" (p. 8); it therefore cultivates better collaboration among healthcare stakeholders in providing improved healthcare services to patients [25].

Compared with other methods such as bar coding, RFID technology offers a more improved mechanism for patient identification, tracking, and tracing within healthcare facilities [26], [27]. It is a viable means for reducing errors in patient care, such as order errors, errors related to adverse drug effects and allergies, patient-medication mismatches, and medication dosage errors [12, 28-31]. Analysts estimate that between $6 \%$ to $12 \%$ of medication errors in the United States result from the ingestion of drugs by patients who are known as allergic to such drugs, as indicated in their medical records [20].

In the context of asset management within the healthcare sector, RFID technology can be used to facilitate the tracking and tracing of pharmaceutical products to avoid the consumption of counterfeit drugs [32]. Counterfeit medications represent not only a threat to patient safety because they may contain dangerous ingredients [33], but also important financial losses for pharmaceutical firms [34]. For example, analysts estimate that about $10 \%$ of the pharmaceutical products worldwide are counterfeit [35], accounting for almost US\$ 75 
billion in financial losses for pharmaceutical firms in 2010 [34]. The fight against this problem explains why US regulatory organizations (e.g., Food and Drug Administration) and states (e.g., California) issued a mandate to pharmaceutical firms to adopt a unique identifier (or e-Pedigree) for each pharmaceutical product that will be used along the supply chain to attest to the origin of the said product. More broadly, RFID technology facilitates the tracking and tracing of critical assets (e.g., infusion pumps, wheelchairs) within the healthcare supply chain [36, 37]. In addition, the same technology can be used to support all steps related to the blood transfusion process (e.g., identification of blood bags at the collection point, tracking and tracing from the collection point to the healthcare facility) [38]. Finally, the adoption and effective use of RFID in the healthcare sector can facilitate the development of predictive maintenance strategies for medical equipment, and therefore enhance proper equipment servicing [39].

Despite such claims, very few studies have been conducted on the relative advantage of RFID technology and its role as an enabler of improved asset management within the healthcare sector. The present study represents an initial attempt to address this issue.

\section{Method and data collection}

This exploratory study intends to examine the relative advantage of RFID technology to assess the potential effect of the technology on asset management-related processes in the healthcare sector. We follow with an assessment of the relative importance of such an effect. Given the exploratory nature of this investigation and the scarcity of related previous studies, a Web-based Delphi technique was used to collect data on the assessments made by RFID experts regarding factors related to the relative advantage of RFID and asset management in the healthcare sector. In this study, an expert is "an individual who has acquired knowledge in a specific domain (e.g., RFID technology) gradually through a period of learning and experience" (p. 5)[40]. The Delphi technique is a viable method for achieving the objectives of this study [41-43]; it is suitable for studies that are constrained by the availability of historical data [44]. Moreover, the technique "lends itself especially well to exploratory theory building on complex, interdisciplinary issues" (p. 446) [44]. The Delphi technique was developed by Rand Corporation [45] as an interactive technique for achieving consensus from a group of experts [46] by "structuring a group communication process so that the process is effective in allowing a group of individuals, as a whole, to deal with a complex problem" (p. 3) [47]. The technique allows for the (a) anonymity of respondents to reduce the effect of dominant individuals; (b) iteration and controlled feedback through multiple rounds to reduce noise; and (c) statistical group response to ensure that the opinion of each panelist within the group of experts is represented in the final response (p. 24) [48]. Finally, the Delphi technique is highly relevant to our study because it is "a particularly valid choice when the problem does not lend itself to precise analytical techniques but can benefit from subjective judgments on a collective basis" (p. 2218) [49].

On the basis of an early study by [39], a review of academic papers, white papers, and industry reports focusing on RFID technology, as well as several discussions with experienced academicians and practitioners, we generated and included a list of 12 processes related to the relative advantage of RFID and 10 processes related to RFID-enabled asset management applications in the healthcare sector in the research questionnaire. For example, the vast majority of items used for RFID-enabled asset management applications were drawn from an early study by[39]. Thereafter, a pilot test of the questionnaire was conducted among five RFID technology researchers to confirm validity, as well as verify the accuracy of the definitions of all the items in the questionnaire.

Three rounds of the Delphi study were run. In the first round, a random sample of 85 respondents was drawn from an aggregate list of authors who have submitted papers on RFID technology to different international conferences and for various special issues of academic journals. A personalized invitation email that explains the objectives of the study, the approximate time required to complete the survey, and the potential number of rounds in the study was sent to each of the respondents. Of the 85 invited authors, 61 agreed to participate. However, only 41 retrieved questionnaires were valid because 20 questionnaires were either incorrectly or insufficiently accomplished (response rate $=67.21 \%$ ). In the second round, one participant who failed to complete the first round expressed his willingness to participate, bringing the number of respondents to 42 . In the third round, 28 panelists participated.

In the first and second rounds, the panelists were asked to evaluate the 12 processes related to the relative advantage of RFID and 10 processes related to RFID-enabled asset management in the healthcare sector using a five-point Likert scale (1=strongly agree, $\quad 2=$ agree, $\quad 3=$ neutral, $\quad 4=$ disagree, and $5=$ strongly disagree). 


\section{Results and discussion}

Among the respondents, $71.4 \%$ were doctorate degree holders; the others held master's (14.3\%), MBA (7.1\%) and bachelor's degrees (4.8\%) (Table $1)$. In terms of business association, $76 \%$ of the respondents were from the academic field, $20 \%$ from the healthcare sector, and $2 \%$ from the consulting and research field (Table 1). respectively, for each round. Finally, the column labeled "SD variation" shows the differences in standard deviations between the two rounds. Variations in standard deviations (SD) and the Kendall coefficient of concordance (W) were used to assess the level of consensus among members of the Delphi study panel. With regard to SD, the "lower the standard deviation is, the higher is the consensus; thus, a 'perfect consensus' on an issue has a standard deviation of zero" (p. 424) [50].

Table 1: Respondent Profile- based on round 2

\begin{tabular}{lcc}
\hline Demographic categories & Frequency & Percentage \\
\hline & & \\
\hline Level of education & 30 & 71.4 \\
Doctorate degree & 6 & 14.3 \\
Master's degree & 3 & 7.1 \\
M.B.A degree & 2 & 4.8 \\
Bachelor's degree & 1 & 2.4 \\
Others & 42 & 100 \\
Total & & 75.6 \\
Business association & 31 & 2.4 \\
Academia & 1 & 9.8 \\
Consulting & 4 & 2.4 \\
Healthcare & 1 & 2.4 \\
Healthcare services provider & 1 & 2.4 \\
Research & 1 & 2.4 \\
Government & 1 & 2.4 \\
meademia \& consulting & 1 & 100 \\
Total & 41 & 28.6 \\
\hline Level of knowledge of RFID technology & & 57.1 \\
I am an RFID technology expert & 12 & 14.3 \\
I have some knowledge of RFID technology & 24 & 100 \\
Total & & 6 \\
\hline
\end{tabular}

In terms of the level of knowledge about RFID technology, $57.1 \%$ of the respondents claimed to have "good knowledge about RFID technology," $28.6 \%$ claimed to be "RFID technology experts," and $14.3 \%$ acknowledged having "some knowledge about RFID technology." Overall, more than $85 \%$ of the respondents had good knowledge of RFID technology (Table 1).

Tables 2 and 3 provide an overview of the key analytical points related to the ranking of items associated with the relative advantage of RFID and RFID-enabled asset management in the healthcare sector, respectively. The "rank" column presents the ranking of all items classified using the mean ranking in the second round of the Delphi study (the reference round for the ranking).

The "mean" and "SD" columns represent the means and standard deviations of the items,
Furthermore, a reduction in SD during the Delphi process shows a high level of consensus among the panel members [50]. For $\mathrm{W}$, a value of $\mathrm{W} \geq 0.7$ indicates strong consensus among the panel members; $\mathrm{W}=0.5$ indicates moderate consensus; $\mathrm{W}$ $<0.3$ shows weak consensus $[51,52]$; and $\mathrm{W}<0.1$ reflects very weak consensus [52].

Thus, we observe a high convergence of consensus in 8 of the 12 processes related to the relative advantage of RFID and in 7 of the 10 processes related to asset management among the Delphi panel members. In addition, we reach perfect consensus among the panel members with regard to the process "detect tampered or unacceptable drugs" in asset management.

Using the Kendall coefficient of concordance from Tables 3 and 4, we can conclude that the level of consensus among the panel members with regard 
to the relative advantage of RFID is weak (W=0.304 in Round 1; $\mathrm{W}=0.338$ in Round 2) and statistically significant for both rounds $\left(\chi^{2}=127.263, \mathrm{p}=0.000\right.$; $\left.\chi^{2}=144.793, \mathrm{p}=0.000\right)$. For the processes related to asset management, the level of consensus among the panel members is very weak (W=0.08 in Round 1 ; $\mathrm{W}=0.07$ in Round 2) and statistically significant for both rounds $\left(\chi^{2}=25.966, \quad \mathrm{p}=0.002 ; \quad \chi^{2}=23.200\right.$, $\mathrm{p}=0.006$ ).

More important, all the top five processes related to the relative advantage of RFID reflect high levels of consensus. These are "improved traceability" $\left(1^{\text {st }}\right)$, "improved operational efficiency" $\left(2^{\text {nd }}\right)$, "provided real-time information access and exchange" $\left(3^{\text {rd }}\right)$, "improved firm internal and external co-ordination of material flows" $\left(4^{\text {th }}\right)$, and "improved visibility" $\left(5^{\text {th }}\right)$. tracking and tracing for access control and decreasing inventory shrinkage" $\left(5^{\text {th }}\right)$.

Furthermore, we were interested in determining the level of agreement between the panel groups (e.g., healthcare practitioners vs. non-healthcare practitioners) or intra-panel agreement. For example, intra-panel agreement was used to examine problems in the interplay of development and IT operations in system development projects [53]. Tables 4 and 5 show a weak and statistically significant level of consensus among the two distinct groups of panel members with regard to processes related to the relative advantage of RFID for the two rounds of the Delphi study.

Table 2: Ranking of processes related to RFID relative advantage

\begin{tabular}{|c|c|c|c|c|c|c|}
\hline \multirow[b]{2}{*}{ Rank } & \multirow[b]{2}{*}{ Relative Advantage Items } & \multicolumn{2}{|c|}{$\begin{array}{l}\text { Round } 1 \\
(n=41)\end{array}$} & \multicolumn{2}{|c|}{$\begin{array}{c}\text { Round } 2 \\
(n=42)\end{array}$} & \multirow{2}{*}{$\begin{array}{c}\text { SD } \\
\text { variation }\end{array}$} \\
\hline & & Mean & SD & Mean & SD & \\
\hline 7 & Improved accuracy & 1.950 & 0.999 & 1.860 & 0.952 & -0.047 \\
\hline 11 & Improved company image & 2.540 & 0.790 & 2.550 & 0.815 & 0.025 \\
\hline 6 & Improved data capacity & 1.820 & 0.874 & 1.830 & 0.863 & -0.011 \\
\hline 4 & $\begin{array}{l}\text { Improved firm internal and external co- } \\
\text { ordination of material flows }\end{array}$ & 1.700 & 0.608 & 1.660 & 0.575 & -0.033 \\
\hline 8 & Improved management decisions & 2.020 & 0.790 & 2.000 & 0.765 & -0.025 \\
\hline 2 & Improved operational efficiency & 1.620 & 0.586 & 1.590 & 0.547 & -0.039 \\
\hline 5 & Improved visibility & 1.760 & 0.943 & 1.690 & 0.897 & -0.046 \\
\hline 1 & Improved traceability & 1.450 & 0.639 & 1.440 & 0.634 & -0.005 \\
\hline 3 & $\begin{array}{l}\text { Provided real-time information access } \\
\text { and exchange }\end{array}$ & 1.590 & 0.591 & 1.600 & 0.587 & -0.004 \\
\hline 9 & Reduced error rates & 2.220 & 0.936 & 2.190 & 0.943 & 0.007 \\
\hline 12 & Reduction in the number of employees & 2.820 & 0.675 & 2.880 & 0.678 & 0.003 \\
\hline \multirow[t]{4}{*}{10} & $\begin{array}{l}\text { Improved collaboration with business } \\
\text { partners }\end{array}$ & 2.420 & 0.781 & 2.440 & 0.808 & 0.027 \\
\hline & Kendall's W & \multicolumn{2}{|c|}{0.304} & \multicolumn{2}{|c|}{0.338} & \\
\hline & Chi-Square & \multicolumn{2}{|c|}{127.263} & \multicolumn{2}{|c|}{144.793} & \\
\hline & Asymp. Sig. & \multicolumn{2}{|c|}{0.000} & \multicolumn{2}{|c|}{0.000} & \\
\hline
\end{tabular}

We also generate a high level of consensus for the top five processes related to asset management; however, three processes are tied at first place: "asset identification of blood bags" $\left(1^{\text {st }}\right)$, "asset tracking and tracing for expiration date and restocking" $\left(1^{\text {st }}\right)$, "inventory management" $\left(1^{\text {st }}\right)$, “asset tracking and tracing to avoid procedural delays" $\left(4^{\text {th }}\right)$, and "asset
For non-healthcare practitioners, we have $\mathrm{W}=0.311, \chi^{2}=109.583, \mathrm{p}=0.000$ in Round 1 and $\mathrm{W}=0.350, \chi^{2}=127.112, \mathrm{p}=0.000$ in Round 2; for healthcare practitioners, we have $\mathrm{W}=0.372$, $\chi^{2}=20.468, \mathrm{p}=0.039$ in Round 1 and $\mathrm{W}=0.372$, $\chi^{2}=20.468, \mathrm{p}=0.039$ in Round 2 .

For the two groups, the following processes are ranked at the same level: "improved traceability" $\left(1^{\text {st }}\right)$, which is the most important process related to 
the relative advantage of RFID technology; "improved collaboration with business partners" $\left(10^{\mathrm{th}}\right)$ and "reduction in the number of employees" $\left(12^{\text {th }}\right)$, which are the two less important processes related to the relative advantage of RFID technology. This ranking is consistent with the early ranking from the entire panel group.

With regard to processes related to asset management applications, a very weak and statistically significant level of consensus is observed among the non-healthcare panel members for the two rounds of the Delphi study $\left(\mathrm{W}=0.093, \chi^{2}=25.91\right.$, $\mathrm{p}=0.002$, for Round 1 and $\mathrm{W}=0.083, \chi^{2}=23.835$, $\mathrm{p}=0.005$ ), but a moderate consensus is achieved among the healthcare members for the two rounds of the Delphi study $\left(\mathrm{W}=0.585, \chi^{2}=21.066, \mathrm{p}=0.012\right.$, for Rounds 1 and 2). This may suggest that for more specific (e.g., "core") processes related to asset management in the healthcare sector, there is an enhanced common understanding of the potential effects of RFID-enabled smart healthcare asset management among the healthcare panel members. One implication of this observation may be the need to carefully select panel members when assessing the effects of RFID technology in a specific business context. conducted within a specific business domain (e.g., retailing, healthcare) because the business effects of the applicability of RFID technology are influenced by its environment.

For the panel of non-healthcare practitioners, the top five asset management-related processes that may benefit from RFID technology as determined in Rounds 1 and 2 are as follows: "asset identification of blood bags" $\left(1^{\text {st }}\right)$, "asset tracking and tracing for expiration date and restocking" $\left(2^{\text {nd }}\right)$, "inventory management" $\left(3^{\text {rd }}\right)$, "asset tracking and tracing for access control and decreasing inventory shrinkage" $\left(4^{\text {th }}\right)$, and "asset tracking and tracing to avoid procedural delays" (5 $5^{\text {th }}$ in Round 1 and $4^{\text {th }}$ in Round 2).

For the panel of healthcare practitioners, the top five asset management-related processes that may benefit from RFID technology as determined in Rounds 1 and 2 are as follows: "maintenance of medical equipment" $\left(1^{\text {st }}\right)$, "inventory management" $\left(2^{\text {nd }}\right)$, "asset tracking and tracing to avoid procedural delays" $\left(2^{\text {nd }}\right)$, "ensure proper equipment servicing" $\left(2^{\text {nd }}\right)$, and "asset tracking and tracing for expiration date and restocking" $\left(5^{\text {th }}\right)($ Table 5$)$.

Table 3: Ranking of processes related to asset management applications

\begin{tabular}{|c|c|c|c|c|c|c|}
\hline \multirow[b]{2}{*}{ Rank } & \multirow[b]{2}{*}{ Asset Management Items } & \multicolumn{2}{|c|}{$\begin{array}{l}\text { Round } 1 \\
(n=41)\end{array}$} & \multirow{2}{*}{\multicolumn{2}{|c|}{$\begin{array}{c}\text { Round } 2 \\
(\mathrm{n}=42)\end{array}$}} & \multirow[t]{2}{*}{$\begin{array}{c}\mathrm{SD} \\
\text { variation }\end{array}$} \\
\hline & & Mean & SD & & & \\
\hline 1 & Asset identification of blood bags & 1.410 & 0.547 & 1.400 & 0.544 & -0.003 \\
\hline 5 & $\begin{array}{l}\text { Asset tracking and tracing for access } \\
\text { control and inventory shrinkage } \\
\text { decrease }\end{array}$ & 1.490 & 0.675 & 1.500 & 0.672 & -0.003 \\
\hline 1 & $\begin{array}{l}\text { Asset tracking and tracing for expiration } \\
\text { date and restocking }\end{array}$ & 1.410 & 0.591 & 1.400 & 0.587 & -0.004 \\
\hline 4 & $\begin{array}{l}\text { Asset tracking and tracing to avoid } \\
\text { procedure delays }\end{array}$ & 1.460 & 0.778 & 1.450 & 0.772 & -0.006 \\
\hline 1 & Inventory management & 1.410 & 0.547 & 1.400 & 0.544 & -0.003 \\
\hline 6 & Maintenance of medical equipment & 1.630 & 0.662 & 1.620 & 0.661 & -0.001 \\
\hline 8 & Materials tracking to avoid left ins & 1.710 & 0.782 & 1.690 & 0.780 & -0.002 \\
\hline 7 & Ensure proper equipment servicing & 1.660 & 0.617 & 1.640 & 0.618 & 0.001 \\
\hline 10 & Detect tampered or unacceptable drugs & 1.730 & 0.708 & 1.710 & 0.708 & 0.000 \\
\hline 9 & Provide ePedigree & 1.750 & 0.732 & 1.700 & 0.740 & 0.008 \\
\hline & $\begin{array}{l}\text { Kendall's W } \\
\text { Chi-Square } \\
\text { Asymp. Sig. }\end{array}$ & & $\begin{array}{l}0.08 \\
25.966 \\
0.002\end{array}$ & & $\begin{array}{c}0.07 \\
23.200 \\
0.006\end{array}$ & \\
\hline
\end{tabular}

This is in line with the observations of [54] (p. 134), who suggest that the study and discussions on RFIDenabled organizational transformation should be
Our results are consistent with early studies on the relative advantage of RFID technology when dealing with counterfeit medicines [35]. In fact, [35] observe 
that "added intelligence", "data sharing between partner" and "real time data collection" were among the top advantages of the technology. Similarly, [55] found that the relative advantage capabilities of RFID such as "data accuracy", "information visibility" and "track and trace" were among the factors that mattered "most" when exploring the potential of RFID technology. However, a study by [56] found that relative advantage was not an important discriminator for adoption in the manufacturing industry (e.g., help lower inventory costs, help quick data capture and analysis and help reduce paperwork). Similarly, [57] found that relative advantage of RFID was not a "decisive influential factor" when exploring RFID adoption in New Zealand's supply chains (e.g., manufacturing, logistics service and retail businesses). These conflicting results require further studies on the relative advantage of RFID technology within various sectors.
In terms of RFID-enabled asset management applications, our results are consistent with the results of prior research on the topic [39]. Indeed, [39] found that "asset identification of blood bags" and "asset tracking and tracing to avoid procedure delays" were among the most important applications to improve quality of care, while "inventory management", "asset tracking and tracing for expiration date and restocking" and "asset tracking and tracing for access control and inventory shrinkage decrease" are among the most important applications to contain healthcare costs.

\section{Conclusion and future research directions}

We used a modified Web-based Delphi study to explore the drivers and challenges of RFID adoption in the healthcare sector.

Table 4: Ranking of processes related to RFID relative advantage by panel type

\begin{tabular}{|c|c|c|c|c|}
\hline & \multicolumn{2}{|c|}{ Round 1: Rank } & \multicolumn{2}{|c|}{ Round 2: Rank } \\
\hline & $\begin{array}{c}\text { Non-Healthcare } \\
\text { practitioners } \\
\left(n_{1}=35\right)\end{array}$ & $\begin{array}{l}\text { Healthcare } \\
\text { practitioners } \\
\quad\left(\mathrm{n}_{2}=5\right)\end{array}$ & $\begin{array}{c}\text { Non-Healthcare } \\
\text { practitioners } \\
\left(n_{1}=36\right)\end{array}$ & $\begin{array}{l}\text { Healthcare } \\
\text { practitioners } \\
\left(\mathrm{n}_{2}=5\right)\end{array}$ \\
\hline Improved accuracy & 7 & 2 & 7 & 2 \\
\hline Improved company image & 11 & 7 & 11 & 7 \\
\hline Improved data capacity & 6 & 4 & 6 & 3 \\
\hline $\begin{array}{l}\text { Improved firm internal and } \\
\text { external co-ordination of } \\
\text { material flows }\end{array}$ & 4 & 6 & 4 & 6 \\
\hline $\begin{array}{l}\text { Improved management } \\
\text { decisions }\end{array}$ & 7 & 7 & 8 & 7 \\
\hline $\begin{array}{l}\text { Improved operational } \\
\text { efficiency }\end{array}$ & 3 & 2 & 3 & 2 \\
\hline Improved visibility & 5 & 7 & 5 & 7 \\
\hline Improved traceability & 1 & 1 & 1 & 1 \\
\hline $\begin{array}{l}\text { Provided real-time } \\
\text { information access and } \\
\text { exchange }\end{array}$ & 2 & 4 & 2 & 3 \\
\hline Reduced error rates & 9 & 10 & 9 & 10 \\
\hline $\begin{array}{l}\text { Reduction in the number } \\
\text { of employees }\end{array}$ & 12 & 12 & 12 & 12 \\
\hline $\begin{array}{l}\text { Improved collaboration } \\
\text { with business partners }\end{array}$ & 10 & 10 & 10 & 10 \\
\hline Kendall's W & 0.311 & 0.372 & 0.350 & 0.372 \\
\hline Chi-Square & 109.583 & 20.468 & 127.112 & 20.468 \\
\hline Asymp. Sig. & 0.000 & 0.039 & 0.000 & 0.039 \\
\hline
\end{tabular}


More specifically, we asked the Delphi panel to assess a list of 12 processes related to the relative advantage of RFID and 10 processes related to RFIDenabled asset management derived from literature. A five-point Likert scale was used by the panelists in the evaluation. Results show that all the top five processes related to the relative advantage of RFID reflect high levels of consensus. These are "improved traceability" $\left(1^{\text {st }}\right)$, "improved operational efficiency" $\left(2^{\text {nd }}\right)$, "provided real-time information access and exchange" $\left(3^{\text {rd }}\right)$, "improved firm internal and external co-ordination of material flows" $\left(4^{\text {th }}\right)$, and "improved visibility" $\left(5^{\text {th }}\right)$. We also yield a high level of consensus for the top five processes related to asset management; however, three processes are tied at first place: "asset identification of blood bags" $\left(1^{\text {st }}\right)$, "asset tracking and tracing for expiration date and restocking" $\left(1^{\text {st }}\right)$, “inventory management" $\left(1^{\text {st }}\right)$, and finally "asset tracking and tracing to avoid procedural delays" $\left(4^{\text {th }}\right)$, "asset tracking and tracing for access control and decreasing inventory shrinkage" $\left(5^{\text {th }}\right)$.
For the intra-panel agreement (e.g., healthcare practitioners and non-healthcare practitioners), results indicate a weak and statistically significant level of consensus among the two distinct groups of panel members with regard to the relative advantage of RFID for the two rounds of the Delphi study. With regard to asset management-related processes, although a very weak and statistically significant level of consensus is observed among the nonhealthcare panel members for the two rounds of the Delphi study, a moderate and statistically significant level of consensus is achieved among the healthcare members for the two rounds of the Delphi study. This result may suggest that for more specific processes related to asset management in the healthcare sector, there is an enhanced common understanding of the potential effects of RFID-enabled smart healthcare asset management among the healthcare panel members. An implication of this observation may be the need to carefully select panel members when assessing the effects of RFID technology in a specific business context.

Table 5: Ranking of processes related to asset management by panel type

\begin{tabular}{|c|c|c|c|c|}
\hline & \multicolumn{2}{|c|}{ Round 1: Rank } & \multicolumn{2}{|c|}{ Round 2: Rank } \\
\hline & $\begin{array}{c}\text { Non-Healthcare } \\
\text { practitioners } \\
\left(n_{1}=35\right)\end{array}$ & $\begin{array}{c}\text { Healthcare } \\
\text { practitioners } \\
\left(\mathrm{n}_{2}=5\right)\end{array}$ & $\begin{array}{c}\text { Non-Healthcare } \\
\text { practitioners } \\
\left(n_{1}=36\right)\end{array}$ & $\begin{array}{l}\text { Healthcare } \\
\text { practitioners } \\
\left(\mathrm{n}_{2}=5\right)\end{array}$ \\
\hline $\begin{array}{l}\text { Asset identification of } \\
\text { blood bags }\end{array}$ & 1 & 7 & 1 & 7 \\
\hline $\begin{array}{lr}\text { Asset tracking and tracing } \\
\text { for access } & \text { control and } \\
\text { inventory } & \text { shrinkage } \\
\text { decrease } & \end{array}$ & 4 & 6 & 4 & 6 \\
\hline $\begin{array}{l}\text { Asset tracking and tracing } \\
\text { for expiration date and } \\
\text { restocking }\end{array}$ & 2 & 5 & 2 & 5 \\
\hline $\begin{array}{l}\text { Asset tracking and tracing } \\
\text { to avoid procedure delays }\end{array}$ & 5 & 2 & 4 & 2 \\
\hline Inventory management & 3 & 2 & 3 & 2 \\
\hline $\begin{array}{l}\text { Maintenance of medical } \\
\text { equipment }\end{array}$ & 9 & 1 & 9 & 1 \\
\hline $\begin{array}{l}\text { Materials tracking to } \\
\text { avoid left ins }\end{array}$ & 6 & 8 & 7 & 8 \\
\hline $\begin{array}{l}\text { Ensure proper equipment } \\
\text { servicing }\end{array}$ & 9 & 2 & 9 & 2 \\
\hline $\begin{array}{l}\text { Detect tampered } \\
\text { unacceptable drugs }\end{array}$ & 6 & 9 & 7 & 9 \\
\hline Provide ePedigree & 8 & 10 & 6 & 10 \\
\hline Kendall's $W$ & 0.093 & 0.585 & 0.083 & 0.585 \\
\hline Chi-Square & 25.91 & 21.066 & 23.835 & 21.066 \\
\hline Asymp. Sig. & 0.002 & 0.012 & 0.005 & 0.012 \\
\hline
\end{tabular}


This study provides a list of processes related to the relative advantage of RFID and processes related to RFID-enabled asset management in the healthcare sector. This study may serve as a starting point for future research on the effect of RFID technology in the said sector. Similarly, the same list may serve as a complete checklist for healthcare managers as they explore the potential of RFID technology. Future research can build upon our list to assess the effect of RFID as an enabler of healthcare asset management at the focal firm level (e.g., within one healthcare facility) and at the inter-firm level (e.g., between multiple healthcare facilities). Furthermore, it would be interesting to examine the effect of improved RFID-based healthcare asset management on healthcare staff performance, service quality, operational efficiency, patient satisfaction, and patient care. Finally, further research must be conducted to assess the cost-benefit of RFID-enabled healthcare asset management projects at the focal firm and inter-firm levels.

\section{References}

[1] United-States-Department-of-Labor, "Healthcare: career guide to industries ", U. S. D. o. Labor, Ed., 2010-11 ed, 2010.

[2] B. Middleton, "Re-engineering U.S. health care with healthcare information technology- promises and peril," vol. $2010,2009$.

[3] C. Wurster, B. P. Lichtenstein, T. Hogeboom, and C. F. Thielst, "Strategic, Political, and Cultural Aspects of IT Implementation: Improving the Efficacy of an IT System in a Large Hospital," Journal of Healthcare Management, vol. 54, pp. 191, 2009.

[4] G. G. Brimacombe, P. Antunes, and J. McIntyre, "The future cost of health care in Canada, 2000 to 2020: balancing affordability and sustainability " The Conference Board of Canada, Toronto, October 2001.

[5] GS1-Australia, "Healthcare industry," 2010.

[6] PITAC, "Revolutionizing health care through information technology," P. s. I. T. A. C. (PITAC), Ed.: National Coordination Office for Information Technology Research and Development, 2004, pp. 36.

[7] M. Bang and T. Timpka, "Ubiquitous computing to support co-located clinical teams: Using the semiotics of physical objects in system design," International Journal of Medical Informatics, vol. 76, pp. S58-S64, 2007.
[8] R. Agarwal, G. Gao, C. DesRoches, and A. K. Jha, "Research Commentary--The Digital Transformation of Healthcare: Current Status and the Road Ahead," INFORMATION SYSTEMS RESEARCH, vol. 21, pp. 796-809, 2011.

[9] E. Ammenwerth, S. Gräber, G. Herrmann, T. Bürkle, and J. König, "Evaluation of health information systems problems and challenges," International Journal of Medical Informatics, vol. 71, pp. 125-135, 2003.

[10] M. Bush, A. L. Lederer, X. Li, J. Palmisano, and S. Rao, "The alignment of information systems with organizational objectives and strategies in health care," International Journal of Medical Informatics vol. 78, pp. 446-456, 2009.

[11] S. Fosso Wamba, "Positioning RFID Technology into the Innovation Theory Landscape: a Multidimensional Perspective Integrating Case Study Approach," in The 15th Pacific Asia Conference on Information systems (PACIS), Brisbane, Australia, 2011.

[12] A. Oztekin, F. M. Pajouh, D. Delen, and L. K. Swim, "An RFID network design methodology for asset tracking in healthcare," Decision Support Systems, vol. 49, pp. 100 $109,2010$.

[13] E. W. T. Ngai, J. K. L. Poon, F. F. C. Suk, and C. C. $\mathrm{Ng}$, "Design of an RFID-based Healthcare Management System Using an Information System Design Theory," Information Systems Frontiers, vol. 11, pp. 405-417, 2009.

[14] E. M. Rogers, Diffusion of Innovation. New York: Free Press, 2003.

[15] E. W. T. Ngai, K. K. L. Moon, F. J. Riggins, and C. Y. Yi, "RFID research: An academic literature review (1995 2005) and future research directions," International Journal of Production Economics, vol. 112, pp. 510-520, 2008.

[16] S. Fosso Wamba, L. A. Lefebvre, Y. Bendavid, and E. Lefebvre, "Exploring the impact of RFID technology and the EPC network on mobile B2B eCommerce: a case study in the retail industry," International Journal of Production Economics, vol. 112, pp. 614-629, 2008.

[17] C. Poirier and D. McCollum, RFID strategic implementation and ROI: a practical roadmap to success: J. ROSS Publishing, 2006.

[18] S. Fosso Wamba, E. Lefebvre, Y. Bendavid, and L. A. Lefebvre, From automatic identification and data capture (AIDC) to "smart business process": a proof of concept integrating RFID: CRC Press, Taylor \& Francis Group, 2008 .

[19] N. Menachemi and R. G. Brooks, "EHR and other IT adoption among physicians: results of a large-scale statewide analysis," Journal of Healthcare Information Management vol. 20, pp. 79-87, 2006. 
[20] K. M. Cresswell and A. Sheikh, "Information technology-based approaches to reducing repeat drug exposure in patients with known drug allergies," Journal of Allergy and Clinical Immunology, vol. 121, pp. 1112 $1117,2008$.

[21] Y.-C. Lu, Y. Xiao, A. Sears, and J. A. Jacko, "A review and a framework of handheld computer adoption in healthcare," International Journal of Medical Informatics, vol. 74, pp. 409-422, 2005.

[22] C. Palacio, J. Harrison, and D. Garets, "Benchmarking Electronic Medical Records Initiatives in the US: a Conceptual Model," Journal of Medical Systems, vol. 34, pp. 273-279, 2009.

[23] Medicare-Payment-Advisory-Commission, "Report to the Congress: New approaches in medicare," M. P. A. Commission, Ed., 2004.

[24] J. Flower, "Digital technology essential and subversive," The Physician Executive, vol. 30, pp. 42-45, 2004.

[25] G. Demiris, L. B. Afrin, S. Speedie, K. L. Courtney, M. Sondhi, V. Vimarlund, C. Lovis, W. Goossen, and C. Lynch, "Patient-centered Applications: Use of Information Technology to Promote Disease Management and Wellness. A White Paper by the AMIA Knowledge in Motion Working Group," Journal of the American Medical Informatics Association, vol. 15, pp. 8-13, 2008.

[26] J. A. Fisher and T. Monahan, "Tracking the social dimensions of RFID systems in hospitals," International Journal of Medical Informatics, vol. 77, pp. 176-183, 2008.

[27] E. Iadanza, F. Dori, R. Miniati, and R. Bonaiuti, "Patients tracking and identifying inside hospital: A multilayer method to plan an RFId solution," presented at Proceedings of the 30th Annual International Conference of the IEEE Engineering in Medicine and Biology Society, EMBS'08 - "Personalized Healthcare through Technology", 2008.

[28] N. P. Menachemi, C. P. Saunders, A. M. D. P. Chukmaitov, M. P. Matthews, R. M. M. Brooks, and K. R. Pietrodangelo, "Hospital Adoption of Information Technologies and Improved Patient Safety: A Study of 98 Hospitals in Florida/PRACTITIONER APPLICATION," Journal of Healthcare Management, vol. 52, pp. 398, 2007.

[29] Y.-J. Tu, W. Zhou, and S. Piramuthu, "Identifying RFID-embedded objects in pervasive healthcare applications," Decision Support Systems, vol. 46, pp. 586 593, 2009

[30] J. Iris, A. Chon, and I. Blake, "Mobile technology at the frontlines of patient care: Understanding fit and human drives in utilization decisions and performance," Decision Support Systems, vol. 46, pp. 634-647, 2009.
[31] C. Thuemmler, W. Buchanan, and V. Kumar, "Setting safety standards by designing a low-budget and compatible patient identification system based on passive RFID technology," International Journal of Healthcare Technology and Management, vol. 8, pp. 571-583, 2007.

[32] P. Booth, P. H. Frisch, and S. Miodownik, "Application of RFID in an Integrated Healthcare Environment," presented at Engineering in Medicine and Biology Society, 2006. EMBS '06. 28th Annual International Conference of the IEEE, 2006.

[33] P. Fuhrer and D. Guinard, "Building a smart hospital using RFID technologies," in European Conference on eHealth. Fribourg, Switzerland, 2006, pp. 131-142.

[34] S. Dahiya, "Counterfeit medicines: the global hazard," Latest Reviews, vol. 6, pp. 1-4, 2008.

[35] E. Lefebvre, A. Romero, L.-A. Lefebvre, and C. Krissi, "Technological strategies to deal with counterfeit medicines: the European and North-American perspectives," International Journal of Education and Information Technologies, vol. 5, pp. 275-284, 2011.

[36] J. Symonds, D. Parry, and J. Briggs, "An RFID-based system for assisted living: Challenges and solutions," Journal on Information Technology in Healthcare, vol. 5, pp. 387-398, 2007.

[37] Y. Bendavid, H. Boeck, and R. Philippe, "Redesigning the replenishment process of medical supplies in hospitals with RFID," Business Process Management Journal, vol. 16, pp. 991-1013., 2010.

[38] V. Kebo, P. Klement, Cerm, aacute, kov, Z., J. Gottfried, Sommerov, M., and A. Palecek, The potential of RFID technology in Blood Center processes, vol.156, 2010.

[39] C. Van Oranje, R. Schindler, L. Valeri, A.-M. Vilamovska, E. Hatziandreu, and A. Conklin, "Study on the requirements and options for Radio Frequency Identification (RFID) application in healthcare,” 2009.

[40] C. Okoli, V. W. A. Mbarika, and S. McCoy, "The Effects of Infrastructure and Policy on e-business in Latin America and Sub-Saharan Africa," European Journal of Information Systems, vol. 19 pp. 5-20, 2010.

[41] R. Snyder-Halpern, "Indicators of organizational readiness for clinical information technology/systems innovation: a Delphi study," International Journal of Medical Informatics, vol. 63, pp. 179-204, 2001.

[42] R. T. Nakatsu and C. L. Iacovou, "A comparative study of important risk factors involved in offshore and domestic outsourcing of software development projects: A two-panel Delphi study," Information \& Management, vol. 46, pp. 57-68, 2009. 
[43] C. Okoli and S. D. Pawlowski, "The Delphi method as a research tool: an example, design considerations and applications," Information \& Management, vol. 42, pp. 15 29, 2004.

[44] S. De Haes and W. Van Grembergen, "An exploratory study into the design of an IT governance minimum baseline through delphi research," Communications of the Association for Information Systems, vol. 22, pp. 443-458, 2008.

[45] M. Steinert, "A dissensus based online Delphi approach: An explorative research tool," Technological Forecasting and Social Change, vol. 76, pp. 291-300, 2009.

[46] S. A. Melnyk, R. R. Lummus, R. J. Vokurka, L. J. Burns, and J. Sandor, "Mapping the future of supply chain management: a Delphi study," International Journal of Production Research, vol. 47, pp. 4629-4653, 2009.

[47] H. A. Linstone and M. M. Turoff, The Delphi Method: Techniques and Applications Mass.: Addison-Wesley Pub. Co., 1975

[48] N. C. Dalkey, "The Delphi method: an experimental study of group opinion," The RAND Corporation, Santa Monica, CA 1969.

[49] D. Sasser and S. Bartczak, "Identifying the benefits of knowledge management in the Department of Defense: a Delphi study," presented at Americas Conference on Information Systems Proceedings, New York, 2004.

[50] I. Park, L. Jinkyu, H. R. Rao, and S. J. Upadhyaya, "Guest Editorial Part 2: Emerging Issues for Secure Knowledge Management: Results of a Delphi Study," IEEE Transactions on Systems, Man \& Cybernetics: Part A, vol. 36, pp. 421-428, 2006.
[51] D. Nevo and Y. E. Chan, "A Delphi study of knowledge management systems: Scope and requirements," Information \& Management, vol. 44, pp. 583-597, 2007.

[52] R. C. Schmidt, "Managing Delphi Surveys Using Nonparametric Statistical Techniques," Decision Sciences, vol. 28, pp. 763-774, 1997.

[53] J. Iden, B. Tessem, and T. Päivärinta, "Problems in the interplay of development and IT operations in system development projects: A Delphi study of Norwegian IT experts," Information and Software Technology, vol. 53, pp. 394-406, 2011.

[54] E. Prater, G. V. Frazier, and P. M. Reyes, " Future impacts of RFID on e-supply chains in grocery retail " Supply Chain Management: An International Journal, vol. 10, pp. 134-142, 2005.

[55] S. Fosso Wamba, B. Keating, T. Coltman, and K. Michael, "RFID Adoption Issues: Analysis of Organizational Benefits and Risks," Wollongong University, vol. http://ro.uow.edu.au/infopapers/821, 2009.

[56] Y.-M. Wang, Y.-S. Wang, and Y.-F. Yang, "Understanding the determinants of RFID adoption in the manufacturing industry," Technological Forecasting and Social Change, vol. 77, pp. 803-815.

[57] C. B. Soon and J. A. Gutiérrez, "RFID Technology Adoption in New Zealand's Supply Chains: A Case Study Approach," Pacific Asia Journal of the Association for Information Systems, vol. 2, pp. 43-66, 2010. 